\title{
RISK-ADJUSTED PERFORMANCES OF WORLD EQUITY INDICES
}

\author{
YIGIT ATILGAN \\ Assistant Professor of Finance, Sabanci University \\ yatilgan@sabanciuniv.edu \\ K. OZGUR DEMIRTAS \\ Associate Professor of Finance, Baruch College, CUNY, and Sabanci University \\ ozgur.demirtas@baruch.cuny.edu
}

\begin{abstract}
This paper investigates whether equity indices of 24 emerging and 28 developed markets compensate their investors equally after taking risk into account. We place special emphasis on downside risk by calculating both nonparametric and parametric value at risk. We find that when all 52 markets are ranked based on their alternative reward-to-risk ratios, almost all of the countries in the top quartile are emerging markets whereas almost all of the countries in the bottom quartile are developed markets. These results are supported by the finding that pooled means of the reward-to-risk ratios are significantly higher for emerging markets compared to those of developed markets. Focusing on the period after the initiation of the recent financial crisis reveals that, although both developed and emerging markets suffered in terms of generating higher returns per unit risk, emerging markets continued to outperform developed markets and the outperformance became more pronounced.
\end{abstract}

JEL Classification Numbers: G10, G11, G12, G15.

Keywords: risk-return relationship, downside risk, value-at-risk, emerging markets, 2008 financial crisis 


\section{INTRODUCTION}

Risk and return characteristics of financial assets have important effects on the portfolio decisions of investors. Risk-averse investors want to choose their portfolio mix such that they take on the minimum risk they can to achieve their desired expected return. In other words, risk-averse investors want to maximize the expected return of their portfolios for every given level of risk. The positive relationship between risk and return is one of the fundamental hypotheses in finance and this trade-off has been documented for various different asset classes. However, finding a positive relation between risk and return does not answer the question of which portfolios generate a higher expected return per unit risk. In this paper, we focus on equity indices of 52 countries and compare their rewardto-risk ratios calculated in alternative ways. Although all of these equity indices represent a diversified portfolio of their respective stock markets, it remains to be seen whether each of them compensate their investors in the same way after taking the risk dimension into account.

The most commonly used measure of return per unit risk is the Sharpe ratio (Sharpe 1966) which is equal to the ratio of the mean excess return of a portfolio to its standard deviation. Standard deviation is a measure of the total risk of a portfolio; therefore a shortcoming of the Sharpe ratio is that it does not differentiate between the upside potential and downside risk. Second, the standard deviation of the realized return distribution is an accurate measure of risk only if the returns are normally distributed. However, past research shows that equity return distributions exhibit asymmetries (i.e. 
they are skewed) and they have fatter tails compared to the normal distribution (i.e. they are leptokurtic). Therefore, we do not suffice with measuring risk by standard deviation and calculate alternative risk measures based on the concept of downside risk for each equity index.

There are a variety of reasons why downside risk is expected to be an important determinant of asset returns. First, Kraus and Litzenberger (1976) and Harvey and Siddique (2000) show that investors demand lower expected returns from assets which make their portfolio returns more positively skewed. Also, Dittmar (2002) suggests a preference for lower kurtosis, i.e. investors demand higher expected returns from investments that make their portfolios more leptokurtic. Downside risk is a function of these higher order moments (Cornish and Fisher 1937). Second, according to the safetyfirst principle of Roy (1952), when investors maximize their return while facing a maximum loss constraint, downside risk will have an effect affects on asset prices. Finally, practical considerations of various market participants such as commercial banks, pension fund managers and credit rating agencies also suggest that downside risk is taken into account when making financial decisions and thus it is a potential determinant of security returns.

Given the importance of downside risk in asset pricing, we construct alternative measures of reward-to-risk which measure risk by both nonparametric and parametric value at risk. The denominator of the nonparametric reward-to-downside risk ratio is equal to the absolute value of the minimum index return over a specific past sample window. The 
denominator of the parametric reward-to-downside risk ratio is based on the lower tail of Hansen's (1994) skewed $t$-density. Both of these alternative measures reflect how much excess return a portfolio generates given a certain probability and magnitude of a left-tail event.

The Sharpe ratio rankings indicate that emerging markets outperform developed markets on average and 12 out the 13 markets in the top quartile are emerging whereas 11 out of 13 markets in the bottom quartile are developed. It is possible that emerging markets are exposed to more downside risk compared to developed markets due to a greater amount of political and financial risk. If emerging markets are faced with a higher probability of collapses, it is possible that adjusting for downside risk rather than total risk can change the reward-to-risk rankings. Once we adjust expected returns for parametric and nonparametric value at risk, we find that the emerging markets continue to populate the top quartile whereas the developed markets lag behind. In other words, emerging markets continue to be superior performers in terms of generating higher returns per unit risk regardless of the risk measure used. Additionally, when we compare the pooled means of the reward-to-risk metrics between emerging and developed markets, we again find that emerging markets have generated higher excess returns per unit risk compared to developed markets and this result is especially pronounced for the time period after the recent financial crisis.

Bali, Demirtas and Levy (2009) uncover an intertemporal relationship between downside risk and expected returns in the U.S. market. Motivated by this study, Atilgan and 
Demirtas (2012) investigate the cross-sections of emerging and developed markets and find evidence for a significantly positive relationship between monthly expected aggregate returns and downside risk for emerging markets. ${ }^{1}$ However, the same relationship is weaker for developed markets. This paper approaches downside risk from a different angle and complements the literature by investigating how much excess return different country equity indices can generate per unit downside risk.

The paper is organized as follows. Section 2 discusses the methodology for calculating the reward-to-risk ratios. Section 3 explains the data and presents the summary statistics. Section 4 discusses the empirical results. Section 5 concludes.

\section{METHODOLOGY}

The first reward-to-risk ratio that we consider is the traditional Sharpe ratio defined as

$$
\text { Sharpe }_{i, t}=\frac{R_{i, t}-R_{f, t}}{\operatorname{StDev} v_{i, t}}
$$

where $R_{i, t}$ denotes the month $t$ return on the equity index $i$ and $R_{f, t}$ is the monthly risk-free rate. The standard deviation for index $i$ is computed using the squared deviations of daily returns from their means. For each month $t$ and index $i$, we calculate the standard deviation on the last trading day of the month based on the daily returns of the past 100 trading days. Specifically,

\footnotetext{
${ }^{1}$ Some studies that investigate the relation between risk and aggregate returns in emerging markets without emphasizing downside risk include Fernandez (2007) and Al Janabi, Hatemi and Irandoust (2010).
} 


$$
\operatorname{StDev}_{i, t}=\sqrt{\frac{1}{99} \sum_{j=0}^{99}\left(R_{i, t-j}-\bar{R}_{i}\right)^{2}}
$$

As a robustness check, we computed the second moment using various other return windows as well as using first order covariance correction and the results are robust to these choices.

Our first measure of downside risk is nonparametric value at risk which measures how much the value of a portfolio could decline in a fairly extreme outcome, if one were to rank order possible outcomes from best to worst. Value at risk attempts to answer the question of how much an investor can expect to lose on a portfolio in a given time period at a given level of probability. For example, if a portfolio of equities has a one-year $1 \%$ value at risk of $-20 \%$, this means that there is a $1 \%$ probability that the portfolio value will decline by more than 20 percent over a one-year period. In our analysis, on the last trading day of each month, we calculate the minimum daily index returns observed during past 100 days of daily data and estimate alternative monthly value at risk measures from the lower tail of the empirical return distribution. Since we use 100 days of data, our nonparametric measure corresponds to $1 \%$ value at risk. The original nonparametric value at risk measures are multiplied by -1 before they are included in the reward-to-risk ratios so that higher magnitudes of value at risk correspond to greater downside risk. After we construct monthly nonparametric value at risk estimates, Sharpe ratios that incorporate these estimates are computed. Specifically, VaRSharpe is defined as:

$$
\text { VaRSharpe }_{i, t}=\frac{R_{i, t}-R_{f, t}}{\operatorname{VaR}_{i, t}}
$$


where $V_{a R_{i, t}}$ is the nonparametric value at risk.

Finally, we calculate a parametric measure of value at risk by utilizing the skewed $t$ density, which accounts for skewness and excess kurtosis in the data. Hansen (1994) introduces a generalization of the Student $t$-distribution where asymmetries may occur, while maintaining the assumption of a zero mean and unit variance. This skewed $t$ (ST) density is given by:

$$
f\left(z_{t} ; \mu, \sigma, v, \lambda\right)=\left\{\begin{array}{l}
b c\left(1+\frac{1}{v-2}\left(\frac{b z_{t}+a}{1-\lambda}\right)^{2}\right)^{-\frac{v+1}{2}} \quad \text { if } z_{t}<-a / b \\
b c\left(1+\frac{1}{v-2}\left(\frac{b z_{t}+a}{1+\lambda}\right)^{2}\right)^{-\frac{v+1}{2}} \quad \text { if } z_{t} \geq-a / b
\end{array}\right.
$$

where $z_{t}=\frac{R_{t}-\mu}{\sigma}$ is the standardized excess market return, and the constants $a, b$, and $c$ are given by

$$
a=4 \lambda c\left(\frac{v-2}{v-1}\right) b^{2}=1+3 \lambda^{2}-a^{2}, c=\frac{\Gamma\left(\frac{v+1}{2}\right)}{\sqrt{\pi(v-2)} \Gamma\left(\frac{v}{2}\right)}
$$

Hansen (1994) shows that this density is defined for $2<v<\infty$ and $-1<\lambda<1$. The density has a single mode at $-a / b$, which is of opposite sign with the parameter $\lambda$. Thus, if $\lambda>0$, the mode of the density is to the left of zero and the variable is skewed to the right, and vice versa when $\lambda<0$. Furthermore, if $\lambda=0$, Hansen's distribution reduces to the traditional standardized t distribution. If $\lambda=0$ and $v=\infty$, it reduces to a normal density. ${ }^{2}$

\footnotetext{
${ }^{2}$ The parameters of the ST density are estimated by maximizing the log-likelihood function of $R_{t}$ with respect to the parameters $\mu, \sigma, v$ and $\lambda$ :
} 
A parametric approach to calculating value at risk is based on the lower tail of the ST distribution. Specifically, on the last trading day of each month, we estimate the parameters of the ST density $(\mu, \sigma, v, \lambda)$ using past 100 days of daily data and then find the corresponding percentile of the estimated distribution. Assuming that $R_{t}=f_{v, \lambda}(z)$ follows an ST density, parametric value at risk is the solution to

$$
\int_{-\infty}^{\Gamma_{S T}(\Phi)} f_{v, \lambda}(z) d z=\Phi
$$

where $\Gamma_{S T}(\Phi)$ is the value at risk threshold based on the ST density with a loss probability of $\Phi$. Equation (6) indicates that value at risk can be calculated by integrating the area under the probability density function of the ST distribution. Specifically, to compute a quantile of a distribution, we utilize the Cornish-Fisher expansion which is a moment-based approximation motivated by the theory of estimating functions, saddlepoint approximations, and Fourier-inversion. The advantage of the Cornish-Fisher (1937) approximation is that it can be computed without any matrix decomposition. It is based on the cumulants, which are the power series coefficients of the cumulant generating function. According to the fourth-order Cornish-Fisher expansion, the lowest daily return can be specified as a nonlinear function of the mean, standard deviation, skewness, and kurtosis of the daily returns. Hence by using rolling estimates of the first four moments of index return distributions we construct parametric value at risk. Thus, Sharpe ratios that incorporate parametric value at risk are defined as:

$$
\log L=n \ln b+n \ln \Gamma\left(\frac{v+1}{2}\right)-\frac{n}{2} \ln \pi-n \ln \Gamma(v-2)-n \ln \Gamma\left(\frac{v}{2}\right)-n \ln \sigma-\left(\frac{v+1}{2}\right) \sum_{t=1}^{n} \ln \left(1+\frac{d_{t}^{2}}{(v-2)}\right)
$$

where $d_{t}=\left(b z_{t}+a\right) /(1-\lambda s)$ and $s$ is a sign dummy taking the value of 1 if $b z_{t}+a<0$ and $s=-1$ otherwise. 


$$
\text { PVaRSharpe }_{i, t}=\frac{R_{i, t}-R_{f, t}}{P \operatorname{VaR} R_{i, t}}
$$

\section{DATA AND SUMMARY STATISTICS}

The data for daily market returns and risk-free rates are obtained from the DataStream Global Equity Indices database. There are 52 markets for which DataStream provides daily index price information. We classify these 52 markets as either emerging or developed. This classification is not standard among different sources, thus we refer to four distinct classifications, namely those of Financial Times and London Stock Exchange (FTSE) Group, Morgan Stanley Capital International (MSCI), Standard and Poor's (S\&P) and Dow Jones. Our sample of developed markets includes equity markets of 28 countries. 25 out of 28 of these markets are listed as developed by all four classification systems. These markets are Australia, Austria, Belgium, Canada, Denmark, Finland, France, Germany, Greece, Hong Kong, Ireland, Israel, Italy, Japan, Luxembourg, Netherlands, New Zealand, Norway, Portugal, Singapore, Spain, Sweden, Switzerland, United Kingdom and United States. Cyprus is listed as developed by MSCI and Dow Jones and never listed as emerging by other sources, thus we treat it as a developed market. South Korea is listed as developed by all classification systems except MSCI which lists it as emerging, thus we also treat it is as a developed market. The final developed market in our sample is Slovenia which is listed as developed by Dow Jones and never listed as emerging by other sources. 
Our emerging market sample contains equity markets of 24 countries. 17 out of 24 of these markets are listed as emerging unanimously by all of the classification systems. These are Brazil, Chile, China, Colombia, Czech Republic, Hungary, India, Indonesia, Malaysia, Mexico, Peru, Philippines, Poland, Russia, South Africa, Thailand and Turkey. Argentina, Bulgaria, Romania, Sri Lanka and Venezuela are never listed as developed, but they are all listed as emerging by Dow Jones. Thus, we treat them as emerging markets. Pakistan is listed as emerging by FTSE and Dow Jones and never listed as developed, so we also treat it as an emerging market. Finally, South Korea is listed as emerging by all classification systems except Dow Jones which lists it as developed, thus we treat is as an emerging market. The sample period starts at January 1973 and ends at December 2011.

We use the total market index item named TOTMK as the national market index for each country. TOTMK series is a value-weighted index where weightings are allocated on the basis of market capitalization. We construct the monthly returns by compounding daily returns calculated from the Return Index (RI) series associated with TOTMK. This series reflects the index values with dividends and distributions. We also use the price data in terms of local currencies to construct the returns to prevent currency risk contaminating the analysis.

Table 1 presents mean, median, standard deviation, minimum, maximum, skewness and kurtosis, Jarque-Bera statistics as well as $25^{\text {th }}$ and $75^{\text {th }}$ percentiles for monthly returns of emerging and developed market equity indices. Panel A presents results for emerging 
markets and Panel B presents results for developed markets. The five emerging markets that have generated the highest mean returns over the sample period are Turkey, Venezuela, Russia, Romania and Mexico. The average monthly returns for these five markets vary between $2.19 \%$ and $4.50 \%$. The five developed markets that have generated the highest mean returns are Hong Kong, Sweden, Norway, United Kingdom and Ireland. The average returns for these markets range from $1.13 \%$ and $1.50 \%$. These figures show that there is a significant difference in average returns between the emerging and developed markets that have generated the highest returns in the past. To put this observation in perspective, one can state that Hungary, which ranks $16^{\text {th }}$ among emerging markets, would have ranked at the top among developed markets with its mean monthly return of $1.51 \%$. Similarly, Czech Republic, the third worst performer among emerging markets, would have found a place in the top five among developed markets with its mean monthly return of $1.17 \%$. The higher average returns associated with emerging markets manifest themselves also at the bottom of the rankings. For emerging markets, the lowest returns are generated by Poland, Taiwan, Czech Republic, Indonesia and Malaysia and these returns vary between 76 basis points and $1.21 \%$. The corresponding range is from 41 to 77 basis points for developed markets and belongs to Slovenia, Japan, Portugal, Switzerland and Germany.

With respect to standard deviations, we observe that four of the five emerging markets with the highest mean returns also have the highest standard deviations with the exception of Mexico. However, none of the emerging markets that have the lowest mean returns find themselves among the five markets with the lowest standard deviations. 
Thus, it is difficult to talk about a one-to-one correspondence between means and standard deviations. Likewise, none of the five developed markets with the highest mean returns are among the five markets with the highest standard deviations, except Hong Kong. The standard deviation figures show that volatility has been higher for emerging markets. For example, when we focus on the five emerging markets with the highest volatility, the standard deviation range is from $11.39 \%$ to $15.38 \%$. The same range is from $8.40 \%$ to $11.87 \%$ for developed markets. This is not surprising as emerging markets are generally exposed to more risk factors.

In line with the standard deviation observations, we find that extreme equity market swings are more pronounced for emerging markets. The minimum return has been less than $-30 \%$ for 14 emerging markets but only for 3 developed markets. Similarly, the maximum return has been greater than $30 \%$ for 19 emerging markets but only for 8 developed markets. The most extreme minimum and maximum monthly returns among emerging markets belong to Romania with $-39.59 \%$ and $84.95 \%$. The largest monthly loss among developed markets belongs to Hong Kong $(-45.77 \%)$ whereas the biggest monthly price appreciation has been observed in Cyprus (72.19\%).

Jarque-Bera statistics are large in magnitude for an overwhelming majority of the indices indicating that most equity index return distributions deviate from normality. However, the asymmetries in the distributions are not extreme. The skewness statistics vary between -0.5357 (South Africa) and 2.2464 (Czech Republic) for emerging markets and the range is from -0.7552 (Switzerland) to 1.5994 (Cyprus) for developed markets. 
Although asymmetries are not severe, one cannot state the same for leptokurtosis. The kurtosis statistics vary between 3.8082 (Mexico) and 22.9182 (Czech Republic) for emerging markets and the range is from 3.5121 (Israel) to 17.4222 (United Kingdom) for developed markets. The existence of fat tails and extreme returns in the distributions of equity index returns highlights the importance of taking downside risk into account when investigating the return generating ability of an equity market after adjusting for risk.

The last three rows of both panels in Table 1 present the average, minimum and maximum sample statistics for the cross-sections of emerging and developed markets and confirm the earlier results. To summarize, emerging market equity indices have higher average returns and volatilities. These observations are consistent with Bekaert and Harvey (1997). Although skewness is not severe, leptokurtosis is pronounced for both country groupings and higher on average for emerging markets.

\section{EMPIRICAL RESULTS}

\subsection{Standard Deviation-Based Sharpe Ratios.}

Table 2 presents the standard deviation-based Sharpe ratios and their standard deviations for 52 equity indices. Mexico has the highest Sharpe ratio which is equal to 0.0811 . Economically, Mexico has generated 8.11 basis points of risk premium per one percent increase in standard deviation. The most striking result from Table 2 is that, after rank ordering the Sharpe ratios among 52 indices, 12 out of 13 markets in the top quartile are emerging markets. The list extends from Mexico to Romania which has a Sharpe ratio of 
0.0519. Sweden holds the $13^{\text {th }}$ place with a Sharpe ratio of 0.0516 and it is the only developed market within the top quartile. Table 1 reveals that emerging markets have higher returns on average but this comes at the cost of higher volatility. The Sharpe ratio rankings in Table 2 imply that this extra volatility burden is not enough to undermine the superior performance of emerging market equity indices. To put this in another way, the lower volatilities of developed market index returns are not enough to compensate for their lower means. Although Turkey and Mexico are among the top five emerging markets according to both mean returns and Sharpe ratios, markets with high Sharpe ratios such as Chile, Bulgaria and Colombia are not among the top five performers based on mean returns. Hence, their lower volatilities are responsible for higher reward-to-risk ratios. Another example is Malaysia which is the fifth worst performing emerging market based on mean returns but ranks in the top quartile based on Sharpe ratios.

When we focus on the bottom quartile of the Sharpe ratio rankings, we see that 11 of the 13 markets with the lowest Sharpe ratios are developed markets. The exceptions are Taiwan and Poland. Similarly, 19 out of 26 markets in the lower half of the rankings are developed. Austria has the lowest Sharpe ratio (0.0093) and Cyprus, Greece, Japan and Germany follow. Developed markets with the highest Sharpe ratios are Sweden, Hong Kong and Luxemburg. Again, there is no one-to-one correspondence between mean return and Sharpe ratio rankings. Although Sweden and Hong Kong are the two best performing developed markets in terms of mean returns, Luxemburg barely makes it to the top ten. Another example is Ireland, which is among the top five developed markets in terms of mean returns but is just above the lowest quartile with a ranking of 38 . 
To summarize, the results from the standard deviation-based Sharpe ratio analysis show that emerging markets are better able to generate excess returns per unit standard deviation compared to developed markets. One final observation is that the average Sharpe ratios are much higher than their time-series standard deviations.

\subsection{Nonparametric and Parametric Value at Risk-Based Sharpe Ratios}

As mentioned earlier, standard deviation is an incomplete measure of risk for equity index returns, whose distributions deviate from normality. This is also evidenced by the highly leptokurtic index returns in Table 1. Moreover, if emerging markets are subject to greater downside risk, the Sharpe ratio rankings in Table 2 that adjust for total risk may be misleading. It is possible that adjusting for downside risk will dissipate the superior performance of emerging markets. Therefore, to take non-normalities and downside risk into account, we calculate alternative Sharpe ratios based on nonparametric and parametric value at risk.

Table 3 presents the results for nonparametric value at risk-based Sharpe ratios. Similar to the findings in Table 2, we observe that all 13 markets in the top quartile based on VaRSharpe ratio rankings are emerging markets. The emerging markets that have the highest VaRSharpe ratios are Chile, Mexico, Bulgaria, Venezuela and Turkey and the ratios vary between 0.0300 and 0.0374 . Economically, the Chilean equity index generates 3.7 basis points of extra excess returns for each $1 \%$ increase in the minimum return observed during the last 100 trading days. In the bottom quartile, 10 out of 13 markets are 
developed, thus developed markets continue to lag behind emerging markets after adjusting for downside risk. Similarly, 17 out of 26 markets in the lower half of VaRSharpe ratio rankings are developed. The worst performing developed markets based on this metric are Germany, Greece, Japan, South Korea and Austria. VaRSharpe ratios for these markets range from 0.0100 to 0.0129 .

The result that emerging markets have higher downside risk-adjusted excess returns is further corroborated in Table 4 based on PVaRSharpe ratios. 11 out of 13 markets in the top quartile are emerging whereas 9 out of 13 markets in the bottom quartile are developed. The best performing emerging markets based on PVaRSharpe ratio are familiar as they also rank at the top quartile in Table 3. Similarly, the worst performing emerging markets (Taiwan, Poland and Pakistan) and developed markets (Germany, Greece and South Korea) also rank at the bottom based on nonparametric value at risk.

The evidence from the downside risk-adjusted expected returns collectively suggests that emerging markets generate higher value at risk-adjusted excess returns compared to developed markets even after placing special emphasis on left-tail risk.

\subsection{Emerging versus Developed Markets and the Financial Crisis}

The analysis up to this point is a country-by-country analysis. In Table 5, we take a broader approach and calculate the means for all reward-to-risk ratios for the two country groupings. Specifically, for both emerging and developed markets, we calculate a cross- 
sectional average across countries in each month and then take a time-series average across months.

Panel A presents the results for the full sample period. As expected, emerging markets outperform developed markets based on all three reward-to-risk metrics. Sharpe ratio comparisons reveal that emerging markets generate about one and a half times as much excess returns per unit standard deviation compared to developed markets $(0.0581$ versus 0.0379). After adjusting for downside risk, emerging markets continue to be the superior performers. VaRSharpe ratios are 0.0256 and 0.0183 for emerging and developed markets, respectively. The gap is even wider for PVaRSharpe ratios of 0.0452 and 0.0223 for emerging and developed markets, respectively. Based on this downside risk metric, emerging markets generate more than twice as much excess returns per unit downside risk compared to developed markets.

Panels B and C split the sample into two periods at September 2008 to enable us to investigate whether the superior performance of emerging markets persists after the peak date of the recent global financial crisis. The results in Panel B are similar to those in Panel A with emerging markets dominating developed markets. Panel C presents some interesting findings. First, we see that both emerging and developed markets experienced declines in all three reward-to-risk metrics in the last part of the sample period indicating that world equity indices were negatively affected by the crisis overall. Second, and more importantly, the decline in the reward-to-risk metrics is more pronounced for developed markets. Sharpe ratio values decrease from 0.0589 in the pre-crisis period to 0.0498 in 
the post-crisis period for emerging markets but the decline is much sharper for developed markets from 0.0406 to 0.0104 . In other words, the average Sharpe ratio decreases by four-fold for developed markets and the average Sharpe ratio for emerging markets is almost five times as high as that for developed markets in the post-crisis period. Similar drops in reward-to-risk metrics in the post-crisis period and the accentuated outperformance of emerging markets are also observed for VaRSharpe and PVaRSharpe ratios. Overall, Table 5 suggests that the superior performance of emerging markets became even more pronounced after the 2008 financial crisis.

\section{CONCLUSION}

We investigate the excess return per unit risk generating ability of equity indices from 52 distinct countries. Due to the potential non-normality associated with stock returns, we give special emphasis to the concept of downside risk in our analysis. Consequently, apart from the traditional Sharpe ratio, we also construct alternative reward-to-risk ratios that consider nonparametric and parametric measures of value at risk as measures of downside risk. We find that emerging markets populate the top quartile and developed markets populate the bottom quartile when the equity indices are ranked based on Sharpe ratios. Downside-risk adjusted expected return rankings also paint a similar picture and show that the superior performance of emerging markets is not due to their greater exposure to tail risk. On average, emerging markets have generated higher risk-adjusted returns throughout the sample period and this superior performance has become more pronounced during the recent financial crisis period. 


\section{REFERENCES}

Al Janabi, M A M, Abdulnasser H J and Irandoust, M (2010), 'Modeling Time-Varying Volatility and Expected Returns: Evidence from the GCC and MENA Regions'. Emerging Markets Finance \& Trade, 46:5, 39-47.

Atilgan, Y and Demirtas, K O (2012), 'Downside Risk in Emerging Markets'. Emerging Markets, Finance and Trade, forthcoming.

Bali, T G, Demirtas, K O and Levy, H (2009), 'Is There an Intertemporal Relation between Downside Risk and Expected Returns?' Journal of Financial and Quantitative Analysis, 44: 883-909.

Bekaert, G and Harvey, C R (1997), 'Emerging Equity Market Volatility'. Journal of Financial Economics, 43: 29-78.

Cornish, E A and Fisher, R A (1937), Moments and Cumulants in the Specification of Distributions. In: La Revue de l'Institute International de Statistique, 4. Reprinted in Fisher, R A (1950). In: Contributions to Mathematical Statistics. Wiley, New York, NY.

Dittmar, R F (2002), 'Nonlinear Pricing Kernels, Kurtosis Preference, and Evidence from the Cross Section of Equity Returns'. Journal of Finance, 57: 369-403.

Fernandez, V (2007), 'Stock Market Turmoil: Worldwide Effects of Middle East Conflicts'. Emerging Markets Finance \& Trade, 43:3, 58-102.

Hansen, B E (1994), 'Autoregressive Conditional Density Estimation'. International Economic Review, 35: 705-730.

Harvey, C R and Siddique, A (2000), 'Conditional Skewness in Asset Pricing Tests'. Journal of Finance, 55: 1263-1295.

Kraus, A and Litzenberger, R H (1976), 'Skewness Preference and the Valuation of Risk Assets'. Journal of Finance, 31: 1085-1100.

Sharpe, W F (1966), 'Mutual Fund Performance'. Journal of Business, 39: 119-138.

Roy, A D (1952), 'Safety First and the Holding of Assets.' Econometrica, 20: 431-449. 


\section{Table 1. Descriptive Statistics}

This table presents descriptive statistics for monthly returns for equity indices of 52 countries. All indices are value-weighted where weightings are allocated on the basis of market capitalization. The indices reflect the dividends and distributions and are based on data in terms of local currencies. The index data are obtained from the DataStream Global Equity Indices database. Panel A presents descriptive statistics for 24 emerging markets. Panel B presents descriptive statistics for 28 developed markets. The last rows of each panel present descriptive statistics for the pooled samples. The descriptive statistics that are presented in the table are the mean, standard deviation, minimum, $25^{\text {th }}$ percentile, median, $75^{\text {th }}$ percentile, maximum, skewness, kurtosis and Jarque-Bera statistic.

Panel A. Emerging Markets

\begin{tabular}{|c|c|c|c|c|c|c|c|c|c|c|}
\hline Country & Mean & St Dev & Min & 25 th & Median & 75 th & Max & Skew & Kurt & JB \\
\hline Argentina & 0.0134 & 0.0940 & -0.3037 & -0.0427 & 0.0134 & 0.0647 & 0.6262 & 1.0781 & 10.5504 & 578.04 \\
\hline Brazil & 0.0171 & 0.0761 & -0.2992 & -0.0296 & 0.0196 & 0.0634 & 0.2281 & -0.3877 & 4.8398 & 35.54 \\
\hline Bulgaria & 0.0205 & 0.1097 & -0.2956 & -0.0384 & 0.0122 & 0.0740 & 0.3628 & 0.3939 & 4.2476 & 12.61 \\
\hline Chile & 0.0177 & 0.0570 & -0.2294 & -0.0164 & 0.0097 & 0.0484 & 0.1905 & 0.3597 & 4.5774 & 34.32 \\
\hline China & 0.0158 & 0.1109 & -0.2657 & -0.0469 & 0.0051 & 0.0800 & 0.4837 & 0.6107 & 5.0247 & 52.65 \\
\hline Colombia & 0.0172 & 0.0661 & -0.1854 & -0.0226 & 0.0149 & 0.0497 & 0.2429 & 0.2438 & 3.8143 & 9.08 \\
\hline Czech Republic & 0.0117 & 0.0825 & -0.2248 & -0.0283 & 0.0109 & 0.0542 & 0.6917 & 2.2464 & 22.9182 & 3856.51 \\
\hline Hungary & 0.0151 & 0.0937 & -0.3486 & -0.0399 & 0.0134 & 0.0596 & 0.6189 & 1.2841 & 12.0800 & 931.23 \\
\hline India & 0.0176 & 0.1035 & -0.3171 & -0.0374 & 0.0130 & 0.0737 & 0.7124 & 1.0986 & 10.6804 & 712.61 \\
\hline Indonesia & 0.0121 & 0.0899 & -0.3188 & -0.0388 & 0.0164 & 0.0646 & 0.3169 & -0.2059 & 4.6173 & 30.75 \\
\hline Malaysia & 0.0128 & 0.0762 & -0.3400 & -0.0228 & 0.0136 & 0.0495 & 0.3326 & 0.0563 & 6.6185 & 172.57 \\
\hline Mexico & 0.0219 & 0.0715 & -0.2471 & -0.0224 & 0.0238 & 0.0655 & 0.2419 & -0.1260 & 3.8082 & 8.24 \\
\hline Pakistan & 0.0143 & 0.0968 & -0.3815 & -0.0415 & 0.0109 & 0.0705 & 0.3328 & -0.1330 & 5.1727 & 47.52 \\
\hline Peru & 0.0144 & 0.0657 & -0.2661 & -0.0195 & 0.0159 & 0.0471 & 0.3068 & -0.0048 & 7.2990 & 169.41 \\
\hline Philippines & 0.0144 & 0.0793 & -0.2423 & -0.0291 & 0.0128 & 0.0511 & 0.3706 & 0.5163 & 6.0894 & 130.86 \\
\hline Poland & 0.0076 & 0.0946 & -0.3237 & -0.0421 & 0.0117 & 0.0579 & 0.3839 & 0.1703 & 6.0693 & 86.63 \\
\hline Romania & 0.0271 & 0.1451 & -0.3959 & -0.0343 & 0.0144 & 0.0777 & 0.8495 & 1.3848 & 9.6854 & 403.65 \\
\hline Russia & 0.0289 & 0.1248 & -0.3554 & -0.0470 & 0.0327 & 0.0848 & 0.6389 & 0.6872 & 6.9128 & 123.26 \\
\hline South Africa & 0.0170 & 0.0664 & -0.3234 & -0.0195 & 0.0195 & 0.0617 & 0.2017 & -0.5357 & 4.7862 & 85.32 \\
\hline Sri Lanka & 0.0166 & 0.0852 & -0.2505 & -0.0315 & 0.0083 & 0.0530 & 0.3972 & 0.7570 & 5.1614 & 86.76 \\
\hline Taiwan & 0.0089 & 0.1020 & -0.3306 & -0.0525 & 0.0072 & 0.0585 & 0.5470 & 0.8215 & 6.7814 & 203.99 \\
\hline Thailand & 0.0153 & 0.0992 & -0.3083 & -0.0346 & 0.0171 & 0.0708 & 0.4258 & 0.2423 & 5.1481 & 61.43 \\
\hline Turkey & 0.0450 & 0.1538 & -0.3944 & -0.0506 & 0.0282 & 0.1085 & 0.7854 & 1.2625 & 6.7456 & 248.26 \\
\hline Venezuela & 0.0323 & 0.1249 & -0.3887 & -0.0234 & 0.0112 & 0.0727 & 0.7024 & 1.2435 & 8.6574 & 426.47 \\
\hline Average & 0.0181 & 0.0945 & -0.3057 & -0.0338 & 0.0148 & 0.0651 & 0.4579 & 0.5443 & 7.1786 & 354.49 \\
\hline Minimum & 0.0076 & 0.0570 & -0.3959 & -0.0525 & 0.0051 & 0.0471 & 0.1905 & -0.5357 & 3.8082 & 8.24 \\
\hline Maximum & 0.0450 & 0.1538 & -0.1854 & -0.0164 & 0.0327 & 0.1085 & 0.8495 & 2.2464 & 22.9182 & 3856.51 \\
\hline
\end{tabular}




\section{Panel B. Developed Markets}

\begin{tabular}{|c|c|c|c|c|c|c|c|c|c|c|}
\hline Country & Mean & St Dev & Min & 25 th & Median & 75 th & Max & Skew & Kurt & JB \\
\hline Australia & 0.0108 & 0.0566 & -0.4024 & -0.0182 & 0.0132 & 0.0444 & 0.2507 & -0.7363 & 10.1558 & 1049.69 \\
\hline Austria & 0077 & 0585 & -0.2717 & -0.0181 & 0.0050 & 0.0303 & 0.3776 & .6756 & 10.7227 & 1208.81 \\
\hline Belgium & 0089 & 0.0499 & -0.2504 & -0.0155 & 0.0109 & 0.0382 & 1986 & -0.5547 & 6.5759 & 275.69 \\
\hline Canada & .0092 & 0.0455 & -0.2218 & -0.0167 & 0.0115 & 0.0376 & 0.1513 & -0.6081 & 5.5348 & 155.45 \\
\hline Cyprus & .0089 & 0.1187 & -0.2987 & -0.0459 & 0.0032 & 0.0582 & 0.7219 & 1.5994 & 10.9480 & 712.62 \\
\hline Denmark & 0.0111 & 0.0543 & -0.1862 & -0.0202 & 0.0120 & 0.0447 & 0.2042 & -0.1400 & 4.2169 & 30.67 \\
\hline Finland & 0107 & 0.0840 & -0.2790 & -0.0396 & 0.0073 & 0.0590 & 0.2963 & 0.1988 & 4.1238 & 17.17 \\
\hline France & 0109 & 0.0600 & -0.2132 & -0.0295 & 0.0133 & 0.0498 & 0.2504 & -0.1063 & 4.0237 & 21.50 \\
\hline Germany & 0077 & 0.0520 & -0.2167 & -0.0210 & & 0.0404 & 0.16 & -0.5417 & 4.9136 & 95.11 \\
\hline Greece & .0098 & 0.0990 & -0.2645 & -0.0466 & 0.0058 & 0.0538 & 0.5940 & 1.5451 & 10.0955 & 668.82 \\
\hline Hong K & 0150 & 0.0951 & -0.4577 & -0.0307 & 0.0161 & 0.0627 & 0.5970 & 0.0627 & 8.0886 & 509.56 \\
\hline Ireland & 0.0113 & 0.0662 & -0.2878 & -0.0268 & 0.0131 & 0.0496 & 0.4132 & 0.1905 & 6.7868 & 284.86 \\
\hline Israel & 0092 & 0.0611 & -0.1823 & -0.0260 & 0.0140 & 0.0465 & 0.1746 & -0.3354 & 3.5121 & 6.89 \\
\hline Italy & 0103 & 0.0706 & -0.2043 & -0.0362 & 0.0054 & 0.0508 & 0.3266 & 0.5588 & 4.7337 & 83.68 \\
\hline Japan & 0044 & 0.0515 & -0.2032 & -0.0252 & 0.0052 & 0.0348 & 0.1941 & -0.1314 & 4.3518 & 37.30 \\
\hline Lux & 0107 & 0.0542 & -0.2741 & -0.0150 & 0.0 & 0.0383 & 0.2033 & -0.6367 & 6.8728 & 168.97 \\
\hline Neth & 0092 & & & & & & & -0.7384 & & 224.06 \\
\hline New Zealand & 0077 & 0.0496 & -0.1612 & -0.0202 & 0.0097 & 0.0327 & 0.2805 & 0.6447 & 7.5055 & 267.20 \\
\hline Norway & 0.0123 & 0.0717 & -0.2705 & -0.0317 & 0.0 & 0.0601 & 0.2431 & -0.5119 & 4.6220 & 59.48 \\
\hline Portugal & 0.0050 & & & & & & & -0.1797 & & 20.73 \\
\hline Singapore & .0086 & 0.0791 & -0.3802 & -0.0305 & 0.0089 & 0.0458 & 0.6173 & 0.6998 & 11.8412 & 1575.82 \\
\hline Slovenia & 0.0041 & 0.0533 & -0.1608 & -0.0246 & 0.0027 & 0.0367 & 0.1376 & -0.2425 & 3.9842 & 8.03 \\
\hline South Korea & 0.0112 & 0.0912 & -0.2832 & -0.0451 & 0.0024 & 0.0594 & 0.5355 & 0.9086 & 6.8346 & 222.08 \\
\hline Spain & 0.0082 & 0.0591 & -0.2870 & -0.0238 & 0.0132 & 0.0456 & 0.1503 & -0.6630 & 4.9866 & 71.78 \\
\hline Sweden & 0.0135 & 0.0671 & -0.2248 & -0.0200 & 0.0145 & 0.0551 & 0.2949 & -0.1338 & 4.3693 & 29.52 \\
\hline Switzerland & 0.0072 & 0.0446 & -0.2383 & -0.0164 & 0.0122 & 0.0349 & 0.1509 & -0.7552 & 5.8347 & 202.90 \\
\hline & 0.0116 & 0.0556 & -0.2565 & -0.0151 & 0.0147 & 0.0425 & 0.5302 & 1.1023 & 17.4222 & 5037.70 \\
\hline United States & 0.0090 & 0.0457 & -0.2075 & -0.0167 & 0.0118 & 0.0389 & 0.1755 & -0.4198 & 4.7720 & 75.61 \\
\hline & 0094 & 0.0042 & & -0.0250 & & 0.0452 & 0.3075 & 0.0268 & 6.7207 & 468.63 \\
\hline Minimum & 0.0041 & 0.0446 & -0.4577 & -0.0466 & 0.0024 & 0.0303 & 0.1376 & -0.7552 & 3.5121 & 6.89 \\
\hline Maximum & 0.0150 & 0.1187 & -0.1608 & -0.0150 & 0.0170 & 0.0627 & 0.7219 & 1.5994 & 17.4222 & 5037.70 \\
\hline
\end{tabular}


Table 2. Standard Deviation-Based Sharpe Ratios

This table presents standard deviation-based Sharpe ratios for equity indices of 52 countries. The index data are obtained from the DataStream Global Equity Indices database. Each row reports the means for each ratio and the standard deviations are presented in parentheses. The numerator of the standard deviation-based Sharpe ratio is equal to the monthly return of the index minus the risk-free rate. The denominator is equal to the standard deviation of daily returns over the past 100 trading days evaluated at the end of each month.

\begin{tabular}{lccccccc} 
& Country & Sharpe & St Dev & & Country & Sharpe & St Dev \\
\hline 1 & Mexico & 0.08110 & $(0.00770)$ & 27 & Thailand & 0.04028 & $(0.00746)$ \\
2 & Chile & 0.07976 & $(0.00963)$ & 28 & Canada & 0.04022 & $(0.00594)$ \\
3 & Turkey & 0.07423 & $(0.00716)$ & 29 & Netherlands & 0.03945 & $(0.00528)$ \\
4 & Bulgaria & 0.07182 & $(0.01499)$ & 30 & Czech Republic & 0.03869 & $(0.00931)$ \\
5 & Colombia & 0.06977 & $(0.01190)$ & 31 & Belgium & 0.03837 & $(0.00631)$ \\
6 & Peru & 0.06590 & $(0.01020)$ & 32 & Denmark & 0.03730 & $(0.00623)$ \\
7 & Venezuela & 0.06354 & $(0.00967)$ & 33 & Pakistan & 0.03666 & $(0.00854)$ \\
8 & Brazil & 0.06121 & $(0.00810)$ & 34 & United States & 0.03639 & $(0.00458)$ \\
9 & Russia & 0.06098 & $(0.00749)$ & 35 & Israel & 0.03614 & $(0.00715)$ \\
10 & Malaysia & 0.05903 & $(0.00806)$ & 36 & Sri Lanka & 0.03601 & $(0.01111)$ \\
11 & South Africa & 0.05807 & $(0.00545)$ & 37 & Portugal & 0.03577 & $(0.00999)$ \\
12 & Romania & 0.05190 & $(0.01000)$ & 38 & Ireland & 0.03560 & $(0.00706)$ \\
13 & Sweden & 0.05158 & $(0.00666)$ & 39 & China & 0.03477 & $(0.00818)$ \\
\hline 14 & Hong Kong & 0.05125 & $(0.00567)$ & 40 & Italy & 0.03473 & $(0.00563)$ \\
15 & Luxemburg & 0.04984 & $(0.00885)$ & 41 & Switzerland & 0.03159 & $(0.00642)$ \\
16 & United Kingdom & 0.04595 & $(0.00485)$ & 42 & Slovenia & 0.03070 & $(0.01376)$ \\
17 & Philippines & 0.04527 & $(0.00861)$ & 43 & Finland & 0.02943 & $(0.00833)$ \\
18 & Norway & 0.04361 & $(0.00610)$ & 44 & Poland & 0.02834 & $(0.00733)$ \\
19 & Spain & 0.04348 & $(0.00727)$ & 45 & Singapore & 0.02526 & $(0.00644)$ \\
20 & Australia & 0.04284 & $(0.00550)$ & 46 & South Korea & 0.02451 & $(0.00616)$ \\
21 & Indonesia & 0.04241 & $(0.00877)$ & 47 & Germany & 0.02371 & $(0.00558)$ \\
22 & France & 0.04237 & $(0.00545)$ & 48 & Japan & 0.01888 & $(0.00546)$ \\
23 & Hungary & 0.04194 & $(0.00843)$ & 49 & Greece & 0.01874 & $(0.00780)$ \\
24 & India & 0.04183 & $(0.00888)$ & 50 & Taiwan & 0.01871 & $(0.00646)$ \\
25 & New Zealand & 0.04180 & $(0.00680)$ & 51 & Cyprus & 0.01703 & $(0.01007)$ \\
26 & Argentina & 0.04081 & $(0.00899)$ & 52 & Austria & 0.00929 & $(0.00843)$
\end{tabular}




\section{Table 3. Nonparametric Value at Risk-Based Sharpe Ratios}

This table presents nonparametric value at risk-based Sharpe ratios equity indices of 52 countries. The index data are obtained from the DataStream Global Equity Indices database. Each row reports the means for each ratio and the standard deviations are presented in parentheses. The numerator of the nonparametric value at risk-based Sharpe ratio is equal to the monthly return of the index minus the riskfree rate. The denominator is equal to the absolute value of the minimum daily index return observed during the last 100 trading days evaluated at the end of each month.

\begin{tabular}{|c|c|c|c|c|c|c|c|}
\hline & Country & VaRSharpe & St Dev & & Country & VaRSharpe & St Dev \\
\hline 1 & Chile & 0.03741 & $(0.00435)$ & 27 & India & 0.01835 & $(0.00340)$ \\
\hline 2 & Mexico & 0.03259 & $(0.00309)$ & 28 & Hungary & 0.01821 & $(0.00310)$ \\
\hline 3 & Bulgaria & 0.03234 & $(0.00627)$ & 29 & France & 0.01818 & $(0.00211)$ \\
\hline 4 & Venezuela & 0.03202 & $(0.00423)$ & 30 & Cyprus & 0.01806 & $(0.00585)$ \\
\hline 5 & Turkey & 0.02997 & $(0.00284)$ & 31 & Thailand & 0.01779 & $(0.00297)$ \\
\hline 6 & Peru & 0.02941 & $(0.00393)$ & 32 & Canada & 0.01706 & $(0.00218)$ \\
\hline 7 & Colombia & 0.02775 & $(0.00428)$ & 33 & Argentina & 0.01705 & $(0.00326)$ \\
\hline 8 & Brazil & 0.02575 & $(0.00333)$ & 34 & Netherlands & 0.01680 & $(0.00203)$ \\
\hline 9 & Malaysia & 0.02537 & $(0.00312)$ & 35 & Belgium & 0.01643 & $(0.00234)$ \\
\hline 10 & Sri Lanka & 0.02455 & $(0.00444)$ & 36 & Czech Republic & 0.01618 & $(0.00328)$ \\
\hline 11 & South Africa & 0.02449 & $(0.00208)$ & 37 & Finland & 0.01530 & $(0.00293)$ \\
\hline 12 & Russia & 0.02420 & $(0.00295)$ & 38 & China & 0.01476 & $(0.00319)$ \\
\hline 13 & Romania & 0.02384 & $(0.00356)$ & 39 & Israel & 0.01462 & $(0.00269)$ \\
\hline 14 & Luxemburg & 0.02384 & $(0.00333)$ & 40 & Italy & 0.01455 & $(0.00213)$ \\
\hline 15 & Philippines & 0.02368 & $(0.00343)$ & 41 & United States & 0.01447 & $(0.00184)$ \\
\hline 16 & Denmark & 0.02198 & $(0.00291)$ & 42 & Switzerland & 0.01416 & $(0.00232)$ \\
\hline 17 & Portugal & 0.02166 & $(0.00428)$ & 43 & Slovenia & 0.01346 & $(0.00499)$ \\
\hline 18 & Indonesia & 0.02118 & $(0.00330)$ & 44 & Singapore & 0.01341 & $(0.00256)$ \\
\hline 19 & Sweden & 0.02108 & $(0.00253)$ & 45 & Austria & 0.01294 & $(0.00361)$ \\
\hline 20 & Hong Kong & 0.02103 & $(0.00226)$ & 46 & Pakistan & 0.01254 & $(0.00289)$ \\
\hline 21 & United Kingdom & 0.02012 & $(0.00193)$ & 47 & Poland & 0.01240 & $(0.00283)$ \\
\hline 22 & Spain & 0.01896 & $(0.00284)$ & 48 & South Korea & 0.01122 & $(0.00239)$ \\
\hline 23 & New Zealand & 0.01890 & $(0.00280)$ & 49 & Japan & 0.01102 & $(0.00216)$ \\
\hline 24 & Australia & 0.01854 & $(0.00211)$ & 50 & Greece & 0.01002 & $(0.00319)$ \\
\hline 25 & Norway & 0.01841 & $(0.00228)$ & 51 & Germany & 0.01001 & $(0.00208)$ \\
\hline 26 & Ireland & 0.01837 & $(0.00263)$ & 52 & Taiwan & 0.00806 & $(0.00262)$ \\
\hline
\end{tabular}




\section{Table 4. Parametric Value at Risk-Based Sharpe Ratios}

This table presents parametric value at risk-based Sharpe ratios for equity indices of 52 countries. The index data are obtained from the DataStream Global Equity Indices database. Each row reports the means for each ratio and the standard deviations are presented in parentheses. The numerator of the parametric value at risk-based Sharpe ratio is equal to the monthly return of the index minus the risk-free rate. The denominator is equal the first percentile of Hansen's (1994) skewed t-density estimated using the daily returns from the last 100 trading days evaluated at the end of each month.

\begin{tabular}{|c|c|c|c|c|c|c|c|}
\hline & Country & PVaRSharpe & St Dev & & Country & PVaRSharpe & St Dev \\
\hline 1 & Bulgaria & 0.05174 & $(0.01001)$ & 27 & Norway & 0.02301 & $(0.00288)$ \\
\hline 2 & Venezuela & 0.04427 & $(0.00573)$ & 28 & Thailand & 0.02234 & $(0.00360)$ \\
\hline 3 & Chile & 0.04262 & $(0.00497)$ & 29 & Spain & 0.02233 & $(0.00325)$ \\
\hline 4 & Romania & 0.04115 & $(0.00760)$ & 30 & France & 0.02170 & $(0.00242)$ \\
\hline 5 & Peru & 0.04080 & $(0.00535)$ & 31 & New Zealand & 0.02147 & $(0.00317)$ \\
\hline 6 & Colombia & 0.03880 & $(0.00671)$ & 32 & Australia & 0.02121 & $(0.00237)$ \\
\hline 7 & Mexico & 0.03820 & $(0.00355)$ & 33 & Belgium & 0.02078 & $(0.00274)$ \\
\hline 8 & Denmark & 0.03679 & $(0.00793)$ & 34 & Cyprus & 0.02001 & $(0.00697)$ \\
\hline 9 & Luxemburg & 0.03627 & $(0.00521)$ & 35 & Canada & 0.01978 & $(0.00248)$ \\
\hline 10 & Turkey & 0.03560 & $(0.00329)$ & 36 & Netherlands & 0.01932 & $(0.00228)$ \\
\hline 11 & Sri Lanka & 0.03439 & $(0.00665)$ & 37 & Slovenia & 0.01913 & $(0.00614)$ \\
\hline 12 & Portugal & 0.03221 & $(0.00721)$ & 38 & Austria & 0.01859 & $(0.00547)$ \\
\hline 13 & Brazil & 0.03064 & $(0.00398)$ & 39 & Switzerland & 0.01789 & $(0.00269)$ \\
\hline 14 & Malaysia & 0.03049 & $(0.00361)$ & 40 & Italy & 0.01780 & $(0.00247)$ \\
\hline 15 & Philippines & 0.03033 & $(0.00433)$ & 41 & Israel & 0.01777 & $(0.00308)$ \\
\hline 16 & Russia & 0.02886 & $(0.00361)$ & 42 & China & 0.01750 & $(0.00369)$ \\
\hline 17 & South Africa & 0.02787 & $(0.00235)$ & 43 & Singapore & 0.01742 & $(0.00307)$ \\
\hline 18 & Indonesia & 0.02717 & $(0.00403)$ & 44 & United States & 0.01720 & $(0.00208)$ \\
\hline 19 & Czech Republic & 0.02650 & $(0.00726)$ & 45 & Finland & 0.01716 & $(0.00340)$ \\
\hline 20 & United Kingdom & 0.02598 & $(0.00256)$ & 46 & Pakistan & 0.01588 & $(0.00336)$ \\
\hline 21 & Sweden & 0.02502 & $(0.00294)$ & 47 & Poland & 0.01517 & $(0.00328)$ \\
\hline 22 & Hong Kong & 0.02443 & $(0.00257)$ & 48 & Japan & 0.01404 & $(0.00262)$ \\
\hline 23 & Hungary & 0.02443 & $(0.00433)$ & 49 & South Korea & 0.01262 & $(0.00275)$ \\
\hline 24 & India & 0.02416 & $(0.00427)$ & 50 & Greece & 0.01225 & $(0.00387)$ \\
\hline 25 & Ireland & 0.02337 & $(0.00327)$ & 51 & Germany & 0.01169 & $(0.00234)$ \\
\hline 26 & Argentina & 0.02327 & $(0.00438)$ & 52 & Taiwan & 0.01059 & $(0.00306)$ \\
\hline
\end{tabular}




\section{Table 5. Emerging versus Developed Markets}

This table presents the average standard deviation-, nonparametric value at risk- and parametric value at risk-based Sharpe ratios separately for pooled samples of emerging and developed market indices. The index data are obtained from the DataStream Global Equity Indices database. The numerator of all ratios is equal to the monthly return of the index minus the risk-free rate. The denominator of the standard deviation-based Sharpe ratio is equal to the standard deviation of daily returns over the past 100 trading days evaluated at the end of each month. The denominator of the nonparametric value at risk-based Sharpe ratio is equal to the absolute value of the minimum daily index return observed during the last 100 trading days evaluated at the end of each month. The denominator of the parametric value at risk-based Sharpe ratio is equal the first percentile of Hansen's (1994) skewed t-density estimated using the daily returns from the last 100 trading days evaluated at the end of each month. Panel A presents the results for the full sample. Panel B presents the results for the time period before September 2008 during which the global financial crisis reached its peak. Panel C presents the results for the time period after September 2008 .

\section{Panel A. Full Sample Period}

\begin{tabular}{cccc} 
& Sharpe & VaRSharpe & PVaRSharpe \\
\hline Emerging & 0.05805 & 0.02557 & 0.04517 \\
Developed & 0.03788 & 0.01832 & 0.02227
\end{tabular}

Panel B. Before September 2008

\begin{tabular}{cccc} 
& Sharpe & VaRSharpe & PVaRSharpe \\
\hline Emerging & 0.05888 & 0.02600 & 0.04712 \\
Developed & 0.04064 & 0.01957 & 0.02388
\end{tabular}

Panel C. After September 2008

\begin{tabular}{cccc} 
& Sharpe & VaRSharpe & PVaRSharpe \\
\hline Emerging & 0.04978 & 0.02130 & 0.02571 \\
Developed & 0.01035 & 0.00578 & 0.00622
\end{tabular}

